\title{
Intradural Metastasis from Cutaneous Squamous Cell Carcinoma Causing Cauda Equina Syndrome
}

\author{
François Mathieu (D), Fan Jiang (D), Jamie R.F. Wilson, Phedias Diamandis, David \\ Choi, Peter Vajkoczy, Michael G. Fehlings (D)
}

Keywords: Cauda equina syndrome, Leptomeningeal carcinomatosis, Lumbar spine, Metastasis, Squamous cell carcinoma

doi:10.1017/cjn.2019.234

Can J Neurol Sci. 2019; 46: 615-620

\section{Case Presentation: Dr Fehlings and Dr Mathieu}

\section{History and Physical Exam}

A 69-year-old Caucasian male was known for a 2-year history of recurrent invasive cutaneous squamous cell carcinoma (SCC) of the skin that had originated in his right temporal region. The patient's past medical history was otherwise significant for remote prostate adenocarcinoma treated surgically, type 2 diabetes mellitus, hypertension, and a 30 pack-year history of smoking. The initial treatment of the SCC had involved primary resection of the lesion and planned radiation therapy of 60 Grey (Gy) to the primary site. His post-resection care was complicated by identification of positive surgical margins as well as early discontinuation of radiotherapy at 52 Gy due to severe periorbital swelling and progressive ptosis of the upper eyelid. Although initial pathology showed no evidence of lymphovascular invasion at the time, a repeat magnetic resonance imaging (MRI) study of the head performed 5 months postoperatively to investigate the periorbital swelling showed evidence of thickening and enhancement of the right supraorbital nerve. More proximally along the trigeminal nerve, there was also evidence of abnormal enhancement of the anterior aspect of the cavernous sinus in continuity with thickening and enhancement of the maxillary division of the nerve (V2) near the right foramen rotundum and the mandibular division (V3) in the right foramen ovale consistent with perineural invasion. In light of the new findings, additional radiation comprised of $70 \mathrm{~Gy}$ in two $35 \mathrm{~Gy}$ fractions was prescribed with the goal of controlling the spread of the disease. Despite treatment, over the course of the following year, the patient developed right facial nerve involvement at the skull base and a rapidly progressing right preauricular mass for which he received a palliative radiation dose of $20 \mathrm{~Gy}$. He concurrently started Cetuximab therapy, a monoclonal antibody targeting epidermal growth factor receptor (EGFR).

The patient came under our care after a 1-week history of difficulty with ambulation, increasing lower extremity neurogenic pain and a new onset of urinary retention, saddle anesthesia, and fecal incontinence over a 4-day period. Physical exam revealed significantly diminished power in the distal lower extremities, the absence of sensation to light touch and pinprick in the saddle region, decreased rectal tone, and an increased postvoiding residual volume. An urgent MRI of the spine revealed leptomeningeal enhancement along the spinal cord and the presence of a $32 \times 14 \mathrm{~mm}$ heterogeneously enhancing intradural mass at the L5-S1 level causing significant compression of the cauda equina (Figure 1).

\section{Discussant: Dr ChOI}

The involvement of the central nervous system by SCC is very rare and noteworthy in this case. The pattern of regional involvement and recurrence of SCC around the skull base and cavernous sinus is also unusual. The involvement of cranial nerves is likely to be due to lymphatic or local venous spread, leading to nerve sheath and leptomeningeal involvement. SCC metastasis to the intradural space was presumably due to direct spread of tumor through the dura of the skull base. Periorbital swelling implies impaired drainage through the ophthalmic veins and cavernous sinus, which was corroborated by the MRI findings.

\section{Case Presentation: Dr Fehlings and Dr Wilson}

\section{Management}

Given the clinical and radiological findings of cauda equina syndrome, our neurosurgical team recommended urgent surgical decompression and resection of the intradural mass. The goal of the operation, which included decompression of the neural elements and collection of tissue specimens for

\footnotetext{
From the Division of Neurosurgery, Toronto Western Hospital, University Health Network, University of Toronto, Toronto, Canada (FM, FJ, JRFW, MGF); Division of Orthopedic Surgery, Toronto Western Hospital, University Health Network, University of Toronto, Toronto, Canada (FJ); Department of Pathology, Laboratory Medicine Program, University Health Network, University of Toronto, Toronto, Canada (PD); Neurosurgical Department, National Hospital for Neurology and Neurosurgery, Queen Square, London, England (DC); Department of Neurosurgery, Charité - Universitätsmedizin Berlin, corporate member of Freie Universität Berlin, Humboldt-Universität zu Berlin, and Berlin Institute of Health, Charitéplatz 1, Berlin, Germany (PV)

Received April 2, 2019. Final Revisions Submitted June 3, 2019. Date of ACCEPTANCE June 15, 2019.

Correspondence to: Michael G. Fehlings MD, PhD, FRCSC, FACS, Division of Neurosurgery and Spinal Program, Department of Surgery, University of Toronto, Krembil Neuroscience Center, Toronto Western Hospital, 399 Bathurst St., Suite 4W-449, Toronto, Ontario, M5T 2S8 Canada. Email: michael.fehlings@uhn.ca
} 


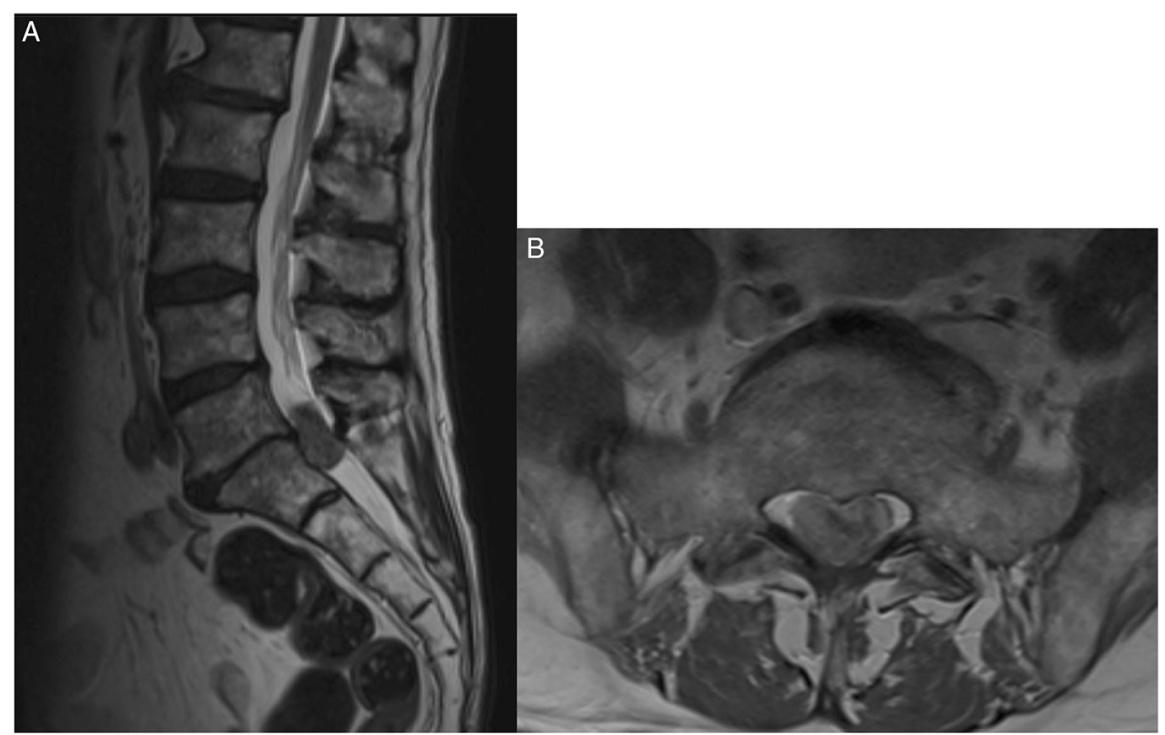

Figure 1: Sagittal and axial MRI scans of the lumbosacral spine. (A) T2-weighted MRI sagittal view showing an intradural mass at the level of L5-S1 measuring $32 \times 14 \mathrm{~mm}$. (B) Axial, T2-weighted MRI view at the level of L5-S1 showing intradural lesion causing significant mass effect and compression of the nerve roots in the cauda equina.

pathological analysis, was discussed with the patient. Consent for laminectomy of L5 and S1, microsurgical resection of the intradural lesion and dural reconstruction was obtained after careful explanation of the associated risks involved with this type of procedure.

Intraoperatively, the cerebrospinal fluid appeared xanthochromic, and the lesion was intimately associated with the cauda equina nerve roots. For this reason, gross total resection was not attempted. Great care was taken while debulking the tumor to spare the nerve roots, and a radical resection with good decompression of the cauda equina was achieved (Figure 2). A watertight dural repair was performed and tested under Valsalva maneuver before closure of the fascia and skin.

\section{Neuropathology: Dr Diamandis}

Histopathological examination of the surgical specimen revealed collections of squamoid cells exhibiting mitotic activity, cellular atypia, prominent nucleoli, and keratinization (Figure 3). While the site of origin of SCCs cannot be resolved by morphologic or immunohistochemical analysis, given the presenting clinical picture and the absence of other tumors from previous screening, this most likely represented a metastasis from the cutaneous origin.

\section{Discussant: DR ChOI}

It is well known that cauda equina syndrome is a neurosurgical emergency and requires immediate surgical decompression. This is more commonly due to acute lumbar disk prolapse, when the severity of sciatic pain is often the driver for the patient seeking medical attention. In subacute cases, presentation may be delayed, but nevertheless it is important to consider emergency decompression as soon as the diagnosis is made. Unfortunately, intradural involvement of the nerve roots by tumor has a worse prognosis than the more usual extradural compression of the cauda equina by a disk prolapse. Although spine surgery has an inherent risk, simple decompressive surgery without fusion or prosthetic implants is usually straightforward and beneficial for the patient. It is very important to maintain good clean technique, avoiding long surgical duration and ensuring robust dural closure. Since this operation aims to improve quality of life (pain and sphincter control in particular), it is essential to minimize the risk of postoperative infection or CSF leakage, which would negate the benefits of timely surgery.

\section{Case Presentation: Dr Fehlings and Dr Jiang}

Postoperatively, the patient reported a resolution of his radicular pain and he was able to ambulate independently with a cane. He continued to experience intermittent urinary incontinence, but no fecal incontinence. The case was discussed at our multidisciplinary tumor board, and adjuvant radiotherapy to the resection area was recommended with close radiological monitoring of the small leptomeningeal deposits located rostrally. At 3 months, the patient reported significant improvement in function and quality of life. He remained ambulatory alternating between a walker and cane and did not experience any recurrence of his radicular leg pain. Unfortunately, since the patient presented as a surgical emergency, no preoperative functional data were available for comparison of improvement. However, as reflected by the self-reported outcome score collected at the follow-up visit, aside from the overall health burden from his underlying condition, he demonstrated mild limitations with an Oswestry Disability Score (ODI) of $22 \%$ and the physical component of the SF-36v2 $2^{\mathrm{TM}}$ Health Survey Scoring being 83\%. Repeat imaging showed a stable residuum, with no evidence of enlargement compared to the immediate postoperative scans (Figure 4). However, due to the heavy underlying tumor burden and progressive clinical decline, the patient unfortunately died 8 months postoperatively. 


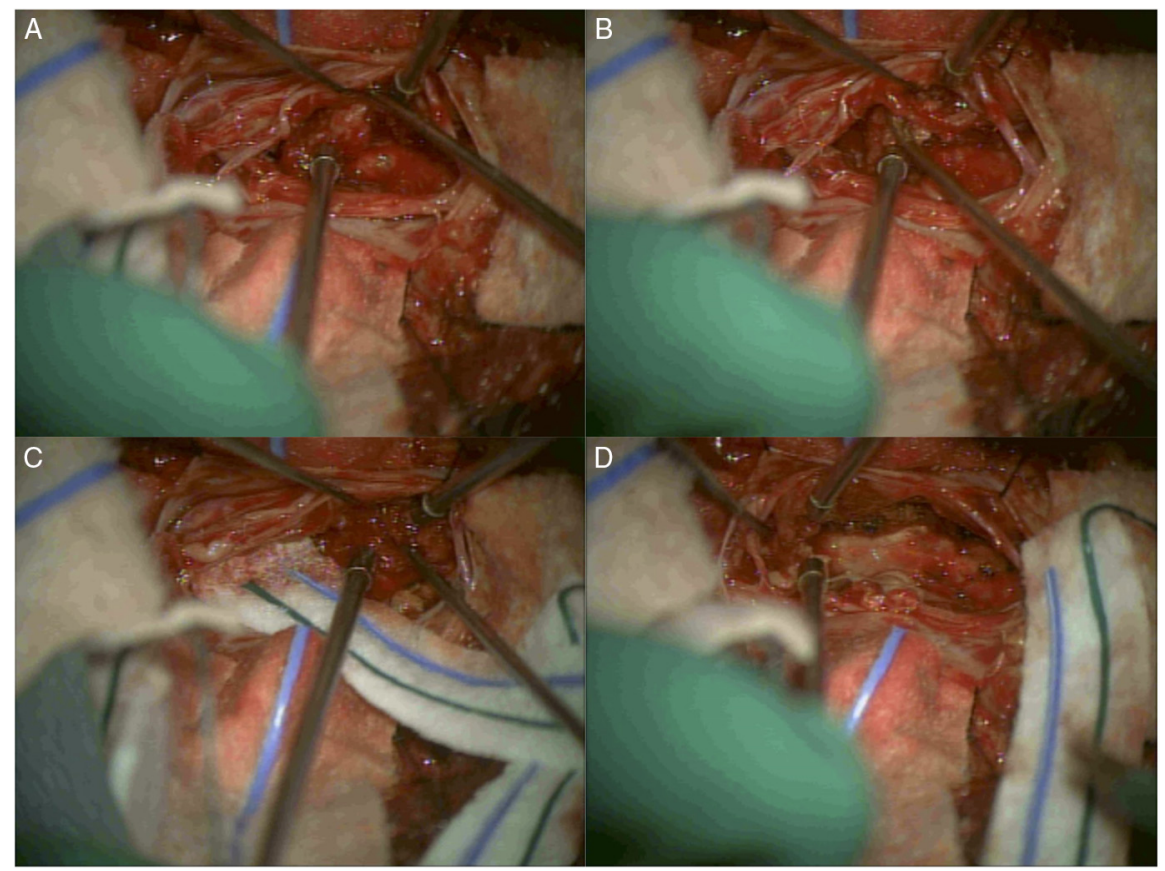

Figure 2: Intraoperative images of surgical resection of the L5-S1 intradural tumor. (A) After durotomy was performed at the level of L5-S1, a tumor was visualized and found to be intimately associated with the nerve roots in the cauda equina. (B) Careful dissection, identifying the nerve roots of the cauda equina and separating them from the tumor mass. $(C)$ Radical resection of the tumor took place while great care was taken to protect and spare the nerve roots. (D) Completion of the resection and good decompression of the cauda equina was achieved.

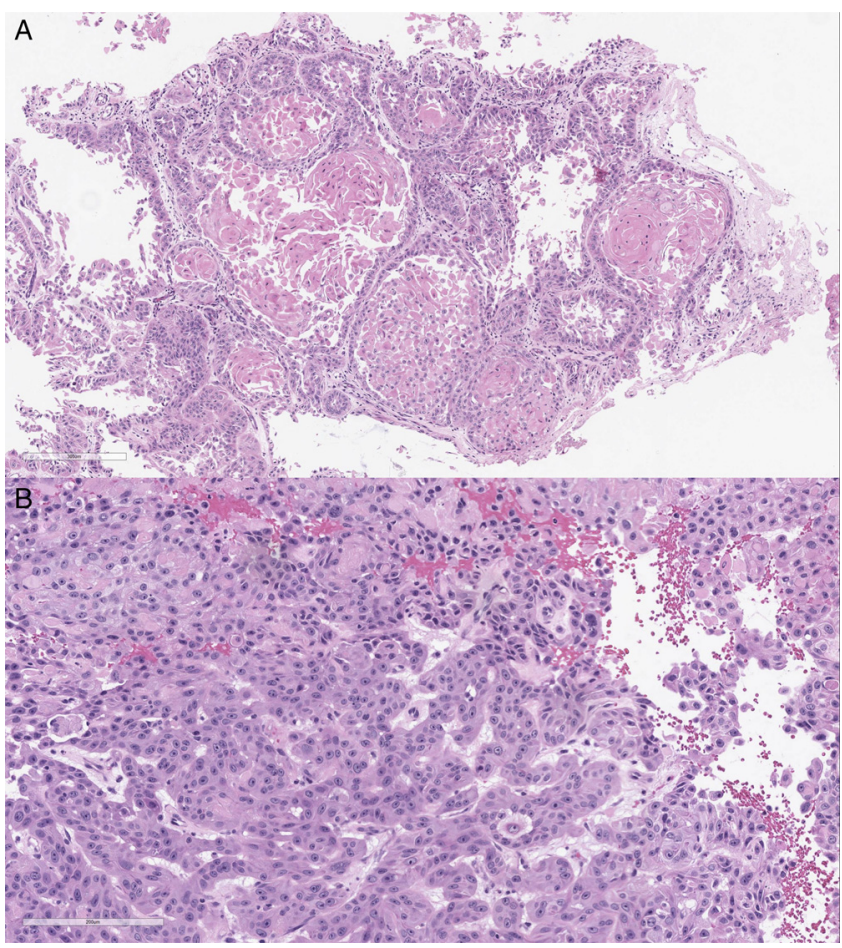

Figure 3: Histopathological examinations showing low power (A) and high power $(B)$ views of an epithelial neoplasm supportive of a metastatic squamous cell carcinoma with atypia, prominent nucleoli, and mitotic activity. The cohesive tumor cells form round islands with a central area of keratinization and a surrounding desmoplastic stromal reaction. 


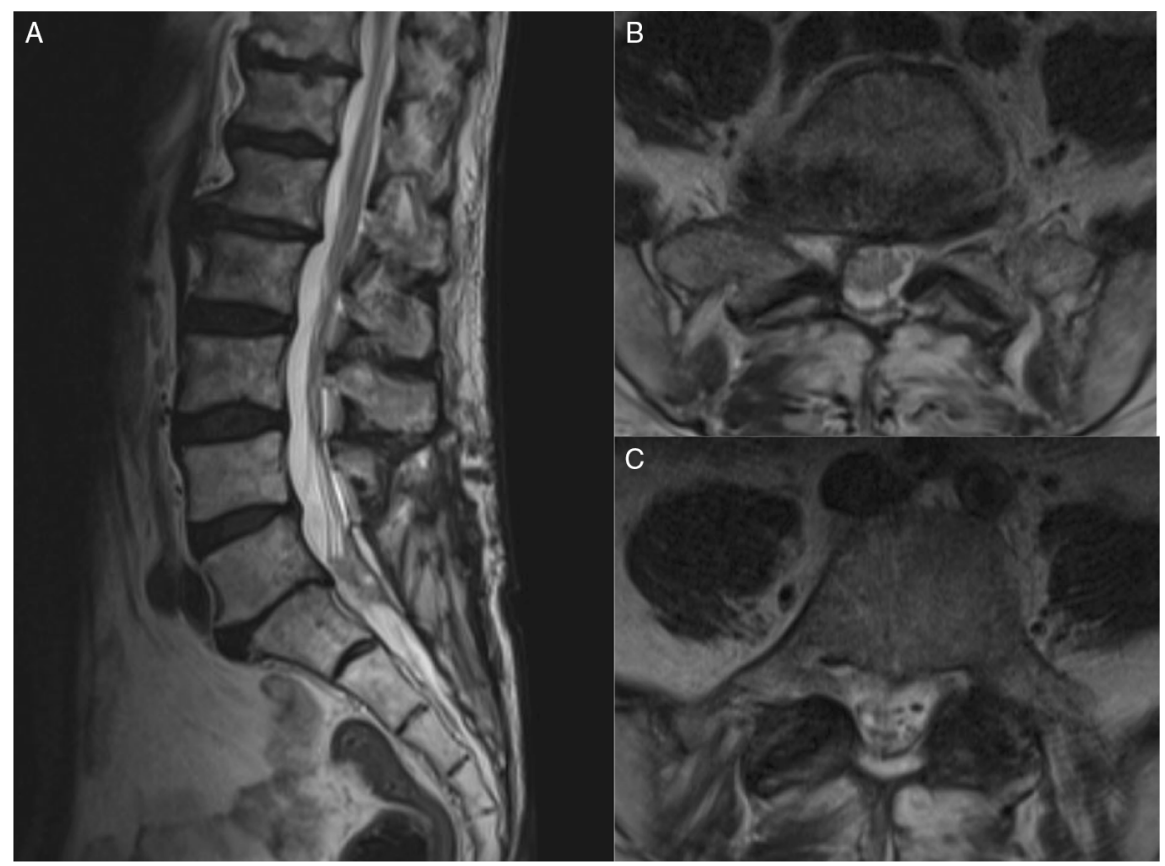

Figure 4: Postoperative MRI was performed. (A) T2-weighted mid-sagittal view of the lumbosacral spine. (B and C), T2-weighted axial views of L5 and S1 showing some residual tumor but good decompression of the cauda equina.

\section{Discussant: DR VAJKOCZY}

In the present case illustration, the authors report a patient with rare intradural metastasis of invasive SCC who presented with acute cauda equina syndrome. The metastasis was resected via a two-level laminectomy at L5/S1 and microsurgical techniques. The outcome was excellent with no further aggravation of the symptoms. This report has several unique features. First, intradural metastases of the spine are rare per se. Most of the metastatic spine disease is localized in the bony and epidural compartments. In contrast, intradural, often intramedullary, seeding is observed in less than $5 \%$ of the cases, both in the clinical and in the experimental setting. ${ }^{1,2}$ In addition, SCC is a tumor that is rarely accompanied by spinal metastases. Secondly, the general bias in the community is to treat patients with intradural metastases by radiotherapy or radiosurgery, with the aim of avoiding potential surgical risks, especially in the case of intramedullary location. ${ }^{1}$ However, surgery provides some advantages that justify surgical resection in select cases including immediate decompression of neural structures and avoidance of radiation-associated side effects and better local tumor control rates in radioresistant tumors. Third, the authors used a two-level laminectomy. The general trend today is to minimize access to the spinal canal when approaching intradural pathologies. Therefore, hemilaminectomies or foraminotomies have become popular. In this case, a traditional laminectomy had the advantage of providing a midline approach of a large and complex tumor, and since the relationship between tumor and nerves is not predictable from the preoperative imaging, a laminectomy can be well justified under the circumstances presented.

\section{Discussant: Dr ChOI}

Although the patient ultimately had a poor prognosis, timely surgery in this case maintained his quality of life and mobility. In fact, there is little justification for delaying simple surgery for cauda equina compression, even in patients with poor prognosis.
The advantages and possible complications of surgery, together with the available alternative options, should be clearly discussed with the patient, as in this case. Occasionally patients may decline surgery, and their informed decision should be respected.

\section{Topic Review and Case Discussion: Dr Fehlings, DR Mathieu, Dr Jiang, AND DR Wilson}

Cutaneous SCC is the second most common form of skin cancer in Caucasians. It arises from epidermal keratinocytes, typically in sun-exposed areas. ${ }^{3}$ Approximately 5\% of patients develop metastases, most commonly to regional lymph nodes. ${ }^{4,5}$ Previously identified prognostic factors for high-risk cutaneous SCC include increased tumor diameter, increased depth of invasion, poor differentiation, a desmoplastic growth pattern, the location of the lesion at the site of a scar, perineural invasion, and host immunosuppression. ${ }^{4-6}$ The reported rate of spread of cutaneous SCC to the leptomeninges and intradural spinal compartment is exceedingly rare, including only three reported cases of metastatic dissemination to the cauda equina and one case of intradural extramedullary spread to the T10 level in the literature. ${ }^{7,8}$ Since no clear surgical indication was present in these cases, treatment involved radiation and medical therapy.

To our knowledge, the case discussed in this conference represents the first report of acute cauda equina syndrome resulting from lumbosacral intradural metastasis of a cutaneous SSC. We speculate - based on the patient's history and corroborating radiographic images - that this is a representation of perineural invasion by a primary tumor followed by leptomeningeal spread. Although perineural spread is observed in up to $5 \%$ of mucosal and glandular SCCs, invasion of the neuroaxis from a cutaneous source is uncommon. ${ }^{9,10}$ Moreover, the leptomeningeal dissemination of cutaneous SCC to the spine is exceedingly rare, with only four cases reported in the literature, 
Table 1: Characteristics of patients with leptomeningeal carcinomatosis from cutaneous SCC

\begin{tabular}{|c|c|c|c|c|c|c|}
\hline Reference & Age (years), sex (M/F) & Tumor origin & Spinal symptoms & Radiographic findings & $\begin{array}{l}\text { Management of } \\
\text { leptomeningeal } \\
\text { metastases }\end{array}$ & Outcome \\
\hline Begemann et al. ${ }^{8}$ & $72, \mathrm{M}$ & $\begin{array}{l}\text { Scalp SCC with spread } \\
\text { to the neck and the } \\
\text { parotid on the right } \\
\text { side }\end{array}$ & $\begin{array}{l}\text { Progressive bilateral } \\
\text { lower extremity } \\
\text { weakness and } \\
\text { numbness }\end{array}$ & $\begin{array}{l}\text { Nodular enhancement } \\
\text { of the thoracic cord, } \\
\text { conus medullaris as } \\
\text { well as the cauda } \\
\text { equina }\end{array}$ & Local fractionated RTx & Death at 6 months \\
\hline Begemann et al. ${ }^{8}$ & $59, \mathrm{M}$ & $\begin{array}{l}\text { SCC of left temporal } \\
\text { skin }\end{array}$ & $\begin{array}{l}\text { Confusion, tongue } \\
\text { deviation, and } \\
\text { worsening } 7 \text { th cranial } \\
\text { nerve palsy }\end{array}$ & $\begin{array}{l}\text { Leptomeningeal } \\
\text { enhancement at the } \\
\text { craniocervical } \\
\text { junction progressed to } \\
\text { involve the entire } \\
\text { spine including the } \\
\text { cauda equina despite } \\
\text { RTx }\end{array}$ & Local fractionated RTx & $\begin{array}{l}\text { Death at approximately } \\
4 \text { months }\end{array}$ \\
\hline Zhu et al. ${ }^{7}$ & $70, \mathrm{M}$ & $\begin{array}{l}\text { Multiple facial SCC } \\
\text { with right V1 and V2 } \\
\text { involvement }\end{array}$ & $\begin{array}{l}\text { Right cavernous sinus } \\
\text { syndrome followed } \\
\text { by left leg paresis }\end{array}$ & $\begin{array}{l}\text { Enhancement of the } \\
\text { cauda equina nerve } \\
\text { roots }\end{array}$ & Local fractionated RTx & N/A \\
\hline Wostrack et al. ${ }^{11}$ & $68, \mathrm{M}$ & Skin SCC & N/A & $\begin{array}{l}\text { IDEM enhancing lesion } \\
\text { at } \mathrm{T} 10\end{array}$ & GTR + adjuvant RTx & N/A \\
\hline Mathieu et al. & $69, \mathrm{M}$ & $\begin{array}{l}\text { SCC right supraorbital } \\
\text { skin with V2 and V3 } \\
\text { involvement }\end{array}$ & Acute CES & $\begin{array}{l}\text { Enhancing compressive } \\
\text { intradural mass at } \\
\text { L5-S1 }\end{array}$ & $\mathrm{STR}+$ adjuvant RTx & $\begin{array}{l}\text { Partial functional } \\
\text { recovery, ambulatory } \\
\text { at } 3 \text { months follow-up }\end{array}$ \\
\hline
\end{tabular}

$\mathrm{SCC}=$ squamous cell carcinoma; $\mathrm{RTx}=$ radiotherapy; N/A=Not available; IDEM=intradural extramedullary; GTR=gross total resection; $\mathrm{CES}=\mathrm{Cauda}$ equina syndrome; STR=subtotal resection.

including three with cauda equina involvement and one endangering the spinal cord at the T10 level (Table 1)..$^{7,8,11}$

In the earlier reports of intradural metastasis of cutaneous SCC, Begemann and colleagues described two cases of leptomeningeal spread of the disease to the cauda equina. ${ }^{8}$ They introduced a 72-year-old man known for SCC involving the scalp with metastases to the right parotid gland and facial nerve presenting with a 6-month history of progressive lower extremity weakness and numbness. MRI of the lumbosacral spine confirmed nodules of enhancement along the thoracic spinal cord, conus medullaris, and cauda equina with cerebrospinal fluid sampling establishing the presence of malignant cells. The patient was treated with fractionated radiation therapy and biweekly high-dose intravenous methotrexate and succumbed to the disease 6 months after being diagnosed with the leptomeningeal spread.

The second case reported by Begemann involved a 59-year-old man with recurrent invasive SCC originating from the temporal skin. ${ }^{8}$ The patient presented 2 years after diagnosis with worsening cranial nerve palsy, deviation of the tongue, and was found to have leptomeningeal disease of the craniocervical junction on MRI. Despite radiation therapy, the disease progressed to the entire spine including the cauda equina, and the patient passed away soon after.

In the case report by Zhu et al. ${ }^{7}$, the authors described a 70-year-old man previously treated for multiple SCCs of the face and neck who developed right-sided cranial neuropathies over 5 years and subsequently presented with a few months history of left leg paresis. ${ }^{7}$ After a series of negative MRIs of the head, an MRI of the brain and spine performed shortly after the patient presented with lower extremity symptoms revealed a right parasellar enhancing mass as well as enhancement of the cauda equina nerve roots. The patient underwent a pterional craniotomy for biopsy of the cavernous sinus lesion, which was consistent with metastatic SCC on histopathological examination. Following the diagnosis, radiotherapy targeting the skull base and lumbosacral spine was delivered, and palliative hospice care ensued.

These clinical cases highlighted the importance of clinical vigilance toward spine involvement in patients with SCC. In all three cases, patients presented with a more indolent clinical course and radiographic evidence of root enhancement in the absence of a compressive lesion. Contrary to previous reports, our case is therefore unique in that the patient presented with a discrete intradural mass severely compressing the cauda equina and resulting in rapid-onset deficits requiring emergent surgical intervention.

Overall, spinal intradural metastases are relatively uncommon, representing approximately $5 \%$ of all spinal metastases, with most of the lesions arising in this region being of primary neurological origin. ${ }^{12}$ Although accounts of cauda equina syndrome with cutaneous melanoma and SCC of the lung, larynx, and anus exist in the literature, ${ }^{13-16}$ it has never been reported with skin SCC. The previously speculated mechanism of intradural infiltration of metastatic lesions includes a direct extension from involved spinal bony elements, hematogenous spread via spinal venous plexuses, or perineural lymphatic spread. ${ }^{17}$ Although in our case, the SCC could have reached the intradural compartment through the hematogenous or venous route, his long-standing history of cranial nerve involvement suggests a pattern of invasion through the cerebrospinal fluid.

While controversies exist in the spine community as to the value of surgical intervention for metastatic epidural disease in patients with poor overall prognosis, this case illustrates that, provided an acceptable risk profile, an excellent clinical outcome can be achieved. This conclusion is further substantiated by a 
recent AO Spine study, ${ }^{18}$ in which operative management of patients with at least 3 months of survival provided significant benefit in clinical recovery and quality of life improvements. Therefore, it is the authors' opinion that given the appropriate clinical context, surgical management is a feasible adjunct to radiation and chemotherapy.

\section{Conclusion}

Although an extremely rare presentation, lower extremity and sphincter dysfunction in patients with invasive skin SCCs should raise the possibility of drop metastases, especially in those with concomitant cranial neuropathies or established perineural spread. In this case, emergent surgical decompression followed by local radiation therapy was associated with significant recovery of function and adequate local spinal tumor control at 3 months postoperatively.

\section{ACKNOWLEDGEMENTS}

MGF wishes to acknowledge support from the Gerry and Tootsie Halbert Chair in Neural Repair and Regeneration and the DeZwirek Family Foundation. JRFW is kindly supported by the Dowager Countess Eleanor Peel Trust and the Ethicon Foundation Travel Award.

\section{CONFLICTS OF INTEREST}

Dr Choi reports interests with the Global Spine Tumor Study Group, DePuy Spine, and the Department of Health, UK - outside the submitted work. The other authors have no conflicts to declare.

\section{Statement of Authorship}

FM and FJ collected and organized all relevant information for the presented case, performed the review of the literature, and wrote the manuscript. JRFW assisted with the review of literature and revised and critically appraised the manuscript. PD provided neuropathological expert commentary and wrote part of the manuscript. DC and PV provided expert commentary on the presented case. MGF supervised the project and revised and critically appraised the manuscript.

\section{REFERENCES}

1. Rades D, Schiff D. Epidural and intramedullary spinal metastasis: clinical features and role of fractionated radiotherapy. Handb Clin Neurol. 2018;149:227-38.
2. Mut M, Schiff D, Shaffrey ME. Metastasis to nervous system: spinal epidural and intramedullary metastases. $J$ Neurooncol. 2005;75(1):43-56.

3. Johnson TM, Rowe DE, Nelson BR, Swanson NA. Squamous cell carcinoma of the skin (excluding lip and oral mucosa). J Am Acad Dermatol. 1992;26(3 Pt 2):467-84.

4. Weinberg AS, Ogle CA, Shim EK. Metastatic cutaneous squamous cell carcinoma: an update. Dermatol Surg. 2007;33(8):885-99.

5. Brantsch KD, Meisner C, Schonfisch B, et al. Analysis of risk factors determining prognosis of cutaneous squamous-cell carcinoma: a prospective study. Lancet Oncol. 2008;9(8): 713-20.

6. Jennings L, Schmults CD. Management of high-risk cutaneous squamous cell carcinoma. J Clin Aesthet Dermatol. 2010;3(4):39-48.

7. Zhu JJ, Padillo O, Duff J, Hsi BL, Fletcher JA, Querfurth H. Cavernous sinus and leptomeningeal metastases arising from a squamous cell carcinoma of the face: case report. Neurosurgery. 2004;54(2):492-8; discussion 8-9.

8. Begemann M, Rosenblum MK, Loh J, Kraus D, Raizer JJ. Leptomeningeal metastases from recurrent squamous cell cancer of the skin. J Neurooncol. 2003;63(3):295-8.

9. Roh J, Muelleman T, Tawfik O, Thomas SM. Perineural growth in head and neck squamous cell carcinoma: a review. Oral Oncol. 2015;51(1):16-23.

10. Leibovitch I, Huilgol SC, Selva D, Hill D, Richards S, Paver R. Cutaneous squamous cell carcinoma treated with Mohs micrographic surgery in Australia II. Perineural invasion. J Am Acad Dermatol. 2005;53(2):261-6.

11. Wostrack M, Pape H, Kreutzer J, Ringel F, Meyer B, Stoffel M. Surgical treatment of spinal intradural carcinoma metastases. Acta Neurochir (Wien). 2012;154(2):349-57.

12. Preciado DA, Sebring LA, Adams GL. Treatment of patients with spinal metastases from head and neck neoplasms. Arch Otolaryngol Head Neck Surg. 2002;128(5):539-43.

13. Cansever T, Kabatas S, Civelek E, Yilmaz C, Caner H. Spinal metastasis of occult lung carcinoma causing cauda equine syndrome with lumbar spinal stenosis. Turk Neurosurg. 2011;21(3):408-12.

14. Cho DY, Wang YC, Chen JT. Intradural metastasis to the cauda equina from carcinoma of the anus. Spine (Phila $\mathrm{Pa}$ 1976). 1995;20(21):2341-4.

15. Thompson SR, Veness MJ, Morgan GJ, Shannon J, Kench JG. Leptomeningeal carcinomatosis from squamous cell carcinoma of the supraglottic larynx. Australas Radiol. 2003;47(3): 325-30.

16. Lindauer S, Martinez M. Intramedullary spinal cord and leptomeningeal metastases presenting as cauda equina syndrome in a patient with melanoma. Journal of Community and Supportive Oncology. 2017;15(4):e224-7.

17. Kokkoris CP. Leptomeningeal carcinomatosis. How does cancer reach the pia-arachnoid? Cancer. 1983;51(1):154-60.

18. Fehlings MG, Nater A, Tetreault L, et al. Survival and clinical outcomes in surgically treated patients with metastatic epidural spinal cord compression: results of the prospective multicenter AOSpine study. J Clin Oncol. 2016;34(3):268-76. 